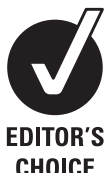

CHOICE

\title{
Ethical lessons from the 'undercover nurse': implications for practice and leadership
}

\author{
Paul Grant
}

\section{Correspondence to}

Dr Paul Grant, Brighton Business

School, University of Brighton,

Moulsecoomb Campus, Lewes

Road, Brighton, East Sussex,

BN2 4AT, UK:

drpaul.grant@doctors.org.uk

Received 22 January 2010

Revised 29 March 2010

Accepted 31 March 2010

\section{ABSTRACT}

Background The case of Margaret Haywood, the 'undercover nurse', is a significant one for the UK's National Health Service (NHS). She investigated complaints made about the Royal Sussex County Hospital and covertly filmed inpatients experiencing care detrimental to their health. The material was subsequently broadcast on the BBC's Panorama programme. It caused a scandal and brought about changes at the hospital, as well a demand for greater clinical leadership. Margaret Haywood was, however, struck off the nursing register for breaching confidentiality and because of the methods she used to blow the whistle.

Methods The authors apply the ethical lenses of purpose, principle, people and power to explore this case. Results This is a morally ambiguous situation in which both the protagonist and the organisation compromised their core values. The undercover nurse used individuals as a means to a 'higher' end, and the Brighton and Sussex University Hospitals NHS Trust are seen to have deviated from the ethical to the business map, in a contradiction of what the health service represents.

Conclusions These deficits can be repaired by reinforcement of the ethics of duty and ideals on a practical level and the involvement of clinicians to lead at a management level, to act as a moral compass.

\section{INTRODUCTION}

One of the most demanding challenges for a responsible leader in the National Health Service (NHS) is the alignment of organisational values with personal, interpersonal and societal values across the spectrum. There is a requirement for moral imagination, an awareness of different values to balance conflicts and the need to generate ethically sound solutions. ${ }^{1}$ This rarely happens in practice.

Complaints had been made about the Royal Sussex County Hospital (RSCH) in Brighton. The complaints were about basic nursing care, feeding and hydrating elderly patients, placing them on commodes or taking them to the lavatory, drawing up care plans, completing fluid balance charts and administration of pain relief on time. The failure to deliver basic nursing care to these patients, many of whom were in the last stages of their lives, rendered many of them miserable. It was so serious especially because it was so fundamental. There was a failure to meet basic human needs. This was the situation that confronted Margaret Haywood $(\mathrm{MH})$ when she was working at the RSCH in Brighton in January 2005.

She was uncomfortable with what she found and complained to her manager to no avail. What made her different from so many others in her position was that she intended to do something about it. Fixed to the underside of her name badge was a small fibre-optic pin camera that was covertly recording everything that happened on the Peel and Stewart ward. 'Everything' included some shocking failures in patient care, a breakdown in the nature of respect and dignity and the humdrum drone of the day-to-day violation of basic ethical standards.

\section{A festering catalogue of neglect. (Professor Phil Barker $^{2}$ )}

In July 2005, the BBC Panorama programme broadcast a documentary highlighting the worst aspects of what $\mathrm{MH}$ had filmed. It caused a sensation - a scandal-and as a consequence she was struck off the nursing register.

Was this right thing to happen? Could she have taken action in a different way? The case of the undercover nurse is a relevant one for the whole of the NHS; we need to understand how such a situation could have arisen in an environment where the core principles are those of care and compassion. Why was there no responsible leadership? What are the implications and the consequences of her actions?

Linda Reid, chair of the panel of the Nursing and Midwifery Council (NMC) that struck off $\mathrm{MH}$ said:

Although the conditions on the ward were dreadful, it was not necessary to breach confidentiality to seek to improve them by the method chosen. (NMC Ruling, 2009 ${ }^{3}$ )

Few decisions of substance have only one moral aspect. This paper aims to explore and analyse the key issues in the case of the "undercover nurse' through a series of ethical lenses in an attempt to clarify the situation.

\section{METHODS}

Varied lenses, used by a photographer, each bring into focus different features of a situation so that they can be more readily inspected. A structured process for identifying and evaluating ethical concerns can correct for the blind spots inherent in many conventional analyses. The goal is to help managers and leaders link more effectively the values they espouse with the choices they actually make.

Four key lenses are useful to look at this type of situation: purpose, principle, people and power. Each lens is associated with a characteristic cluster of questions that can help us see more clearly ethical problems that a management/economic/policy perspective might obscure. This choice of approach is supported by the simplicity and elegance of the 
lenses: they are all-encompassing and create the metaphorical decision-making compass. It is also a useful alternative to the traditional Western bioethics format, all components of which are subsumed into our holistic overview.

1. Purpose: the ethics of ends and means or pragmatism.

2. Principle: are the actions consistent with relevant principles, the ethics of duty and ideals?

3. People: what are the consequences for the people involved?

4. Power: concerns the protagonists' authority and ability to act, their moral right and material resources to act.

We will therefore undertake a description and critical analysis of the case, looking through each of these lenses in turn.

\section{DISCUSSION}

\section{Purpose}

$\mathrm{MH}$ made it clear that she had a purpose in supporting the Panorama team-that is:

To safeguard the welfare of all vulnerable people in care.

$\mathrm{MH}$ wanted to highlight the problems at the RSCH; she had tried the normal channels without success. She partook in an undercover filming exercise and subsequently showed her raw footage to the Panorama production team, who selected and edited the extracts they wished to use. $\mathrm{MH}$ then provided the film-makers with contact details for those patients, which made it possible for the $\mathrm{BBC}$ lawyers to contact the patients or their relatives to obtain their consent for broadcast.

The filming was seen as justifiable by the NMC, given the serious nature of the problems exposed. ${ }^{3}$ Their decision would appear to be based on the feeling that the ends justified the means. This conflicts with Kant's categorical imperative:

\section{Act only according to that maxim whereby you can at the same} time will that it should become a universal law. (Kant, 1785 ${ }^{4}$ )

By covertly filming, she violated patient rights and if this practice is extended to its logical conclusion, it would be justifiable to film all patients in hospital at any given time just in case there were failings in their care and then requesting consent after the event. $\mathrm{MH}$ and by extension the NMC violate Kant's first, second and third moral maxims.

Undoubtedly her actions contributed to short- and long-term improvements in patient care, but it may be that the actions were expedient rather than moral.

The actual reason behind the NMC's striking off was the provision of confidential material to a third party. Breaching confidentiality may be acceptable in certain circumstances where there is a clear public interest in doing so. Healthcare professionals have an obligation to take such actions and indeed the trust's whistle-blowing policy actually supports this. ${ }^{5}$ Such actions can be justified only if the dangers inherent in not doing so are equally extreme. There really must be no alternative. In the view of the NMC panel, MH's actions did not meet such tests.

The realistic alternatives in such a situation would presumably include:

- completing an incident form

- complaining to senior management

- contacting the Department of Health directly

- contacting her member of parliament

- contacting another form of the media-for example, a newspaper

- declining to pass confidential contact details on to the production crew (however, this would have meant that the documentary makers would not obtain consent and would have to anonymise the patients shown)

- considering negotiating with the chief executive with the completed video footage and demanding change.

It is unlikely that change would have been brought about on such a scale if $\mathrm{MH}$ had proceeded with the first four options. Also, there is very real risk of the issue being quashed, and much 'whistle-blowing' literature reports the significant threat of job losses or disciplinary procedures. ${ }^{6} 7$

The other options represent reasonable approaches to bringing the matter to public attention, and under the policy for making external contact with the media the whistle-blower has to act 'reasonably'.

We know that the visual medium of television in a serious documentary format provided significant impact; in this instance we were able to see elderly patients screaming in pain as they had not received their medications, incontinent patients lying in their own urine and excrement and one woman with cancer who was unable to eat-she later died alone, unnoticed. More than 4 million people watched it and over 2000 phoned in to complain to the BBC; questions were subsequently asked in the House of Commons. A newspaper-based story might not have been as hard-hitting. It is difficult to conceive of any other avenue that could have achieved her purposes so successfully; one therefore has to question the validity of the NMC's judgement.

The panel concluded that, for it to be 'essential' for $\mathrm{MH}$ to breach confidential information: she must first have exhausted all other avenues of addressing the inadequacies on the ward; alternatively, there must be an immediate need. So far as the latter is concerned, there was no immediate release of her film, since the Panorama programme was not broadcast for some time. One could argue that she should have phoned a tabloid newspaper straight away and given them an exclusive, but, as we have discussed, she would not have as successfully fulfilled her purpose. This brings us back to the using of the right means to her ends. Does 'right' here mean 'morally right' or 'most effective'? Essentially, $\mathrm{MH}$ felt that getting greater impact through the delay of several months was more important than bringing an immediate halt to the inadequacies of care via a tabloid exposure.

Therefore, she did what she thought was best for the greatest impact, but this corroded her principles. The immediate route would have highlighted the problem and led to faster change, and $\mathrm{MH}$ would have still fulfilled her purpose, although perhaps not to the same degree. This option is a compromise, but an ethically sound one. The NMC were concerned that $\mathrm{MH}$ had 'bought in' to the documentary production and acted at the behest of the filmmakers rather than her own better judgement as a nurse caring for patients:

There was a conflict of interests here and the registrant followed her role as a person engaged by the Panorama programme rather than her duties as nurse.

\section{Principle}

Were MH's actions consistent with the relevant principles, the ethics of duty and ideals? Under a normative analysis it is useful to look at the NMC's professional code of conduct. ${ }^{8}$ This states that the people in your care must be able to trust you with their health and well-being. To justify that trust, a nurse must

- make the care of people your first concern, treating them as individuals and respecting their dignity 
- work with others to protect and promote the health and wellbeing of those in your care, their families and carers, and the wider community

- provide a high standard of practice and care at all times

- be open and honest, act with integrity and uphold the reputation of your profession.

These are the aspired-to ideals of the nursing profession. $\mathrm{MH}$ did make the care of people her first concern above all others, but one could argue that the individuals shown in the programme were themselves compromised and undignified and did not experience any net benefit.

Regarding the second point, she did indeed work with others to protect and promote the health and well-being of those under her care, as well as those of the wider community who are equally at risk of having the same very poor care in future (although the NMC code probably doesn't include the BBC). This throws the NHS establishment into stark relief. The organisation that is supposed to have the responsibility for care is unable to deal with fundamental flaws in the delivery of said care, one of the founding principles of the NHS. MH provided specific evidence of uncaring behaviour-for example, nurses eating patients' food in the kitchen while some patients who were unable to feed themselves went hungry-and $\mathrm{MH}$ has made the implicit (elderly patients receive dreadful treatment) explicit. It was the media exposure that was required to provoke a national sharp intake of breath.

Some commentators believe that the biomedical model/ ideology is a form of colonial patronage that is becoming more and more influential in nursing. ${ }^{9}$ This suggests that nurses are moving away from their 'true' role ${ }^{10}$ and that the introduction of nursing as a degree will arguably bring about a generation of nurses 'too posh to wash'. 11 Holmes and Roy believe that a postcolonial approach to nursing constitutes an 'efficient tool for disrupting the colonising effects' of the external biomedical discourse, in order to return to a purer definition of nursing. ${ }^{9}$

$\mathrm{MH}$ violated the fourth principle of her own code of conduct. She deliberately sought out excessive examples of poor practice on an overstretched ward. In terms of integrity as a theoretical and ethical concept, yes, she was consistent in her actions and they were no doubt allied to her value system and partly the principles of nursing. This is interesting, as it demonstrates that $\mathrm{MH}$ could be described as a moral hypocrite: she strongly acted according to one or two of her core principles but ignored others when they got in the way. However, one could also define integrity in this situation as a measure of willingness to adjust a value system to improve its consistency when expected results appears incongruent with observed outcomes-that is, in a hospital setting we should provide the absolute best care for patients and this means making a noise or changing our principles to obtain the best outcome. As always, ethics in practice is strongly contingent, provisional and contextualised. The question of whether $\mathrm{MH}$ upheld the reputation of her profession could be the subject of a whole essay in itself. In late 2009, after a successful appeal and being reinstated, $\mathrm{MH}$ received the Nursing Standard Patient Choice Award, an element of popular approval that would satisfy the Wednesbury doctrine. ${ }^{12}$

\footnotetext{
Mrs Haywood felt strongly enough about the standards of care she was witnessing to put her job on the line ... Maybe her decision to approach Panorama was questionable, but no one can deny that it was probably the most effective way to instigate change, which would immediately benefit patients. In nominating Mrs Haywood, I would like to help send the message to the NMC that they are out of touch with the wishes of the public they deem to protect. (Nursing Standard, 2009) ${ }^{13}$
}

\section{People}

What are the consequences for the people involved? In a sense she gave voice to the voiceless and shone the media spotlight, showing them to be unwell and dehumanised. But this was allowable due to the waiver that is post hoc informed consent. $\mathrm{MH}$ failed to mitigate the potential harms while she was pursuing mutual gains for the greater good. There were certainly less harmful alternatives, as we have already discussed.

After the broadcast, the trust issued an apology for "the serious lapses in quality of care'. This in no way rectifies the failings or distress that had been caused and that the trust was responsible for. For them the implications were significant and there has subsequently been restructuring of the geriatric wards, the senior executive team, the policies regarding the working practices and quality standards of the nursing staff.

As for $\mathrm{MH}$ herself, she was struck off the nursing register in a very high-profile and controversial manner.

The most I was expecting was a caution.

We mustn't forget to mention all the non-whistle-blowers. Were the majority of other healthcare professionals at the RSCH ignorant, complicit or too tolerant? An RCN national poll in May 2009 showed that 63\% of nurses had reported their concerns about various systemic inadequacies to management. ${ }^{14}$ Only 29\% said that immediate action had been taken, and in $35 \%$ of complaints no action had been taken. Three-quarters of respondents said they feared victimisation or reprisals, while more than a fifth had been actively discouraged from reporting their concerns. The dominant feeling was that the key focus of the NHS-patients and their holistic well-being-was being sacrificed in favour for financial outcomes and arbitrary performance indicators.

\section{Power}

Next we consider MH's authority and ability to act, her moral right and material resources. She was an insider, a member of a respected profession with the ability, skills, clout and energy to carry out the proposed plan. One could argue that all decent human beings have a responsibility to act under such circumstances and it would be wonderful if this type of situation was unique, but it is still present in the NHS today.

\section{All that is necessary for evil to triumph is that good men stand by} and do nothing. (Edmund Burke, alluded to by Martin Porter. $)^{15}$

$\mathrm{MH}$, as discussed, acted in line with the moral certainty that she knew what she was doing was the right thing. The authority of her actions was supported by but not dependent on her duties as a nurse, and her ability to act was enhanced by the support of a television production crew.

$\mathrm{MH}$ had power over the powerless and incapacitated. If they were competent, fit consumers of healthcare, they would have the right to complain. But in reality, geriatric patients are on a spectrum of cognitive and functional disability, their locus of control is displaced and they are often uncomplaining victims of hegemony, allowing anyone with a camera to come along, put them on show and become objectified, homogenised and dehumanised.

It is therefore controversial to decide whether MH's moral right can assert itself in such a way. She dislocated her patients' rights of self-determination. Irrespective of the outcome, there is clear ethical disquiet in this case of the undercover nurse, which represents a dilemma between appropriate whistle-blowing and the principles of autonomy and non-maleficence on the one hand versus justice and beneficence on the other. 


\section{CONCLUSIONS}

Most corrupt, illegal and immoral practices go undetected within any organisation, because employees, aware that these things are going on, fear the consequences of reporting them through existing internal channels. When the Piper Alpha oil platform caught fire in 1988, 167 people were killed. Workers had known about the safety risks but had not reported them for fear of job losses.

To the extent that moral concerns have come into managers' decision-making processes, they have generally taken the form of smell, sleep and newspaper tests:

- Does it smell okay?

- Will it keep me awake at night?

- How would it look on the front of a newspaper?

Not long before courageous employees blew the whistle on Enron, the company was hailed as one of the most innovative and best companies to work for (they even had a state-of-the-art ethics programme). The chief executive officer, Jeffrey Skilling, was felt to be a good leader, not in a moral sense but in a business sense, because he delivered results-in other words, he was effective. $^{16}$

The fallout from the Panorama programme led to an internal investigation at the RSCH. This identified

the need for new policies, staff training and ward leadership.

Things have improved dramatically since these scenes were shot.

(Peter Coles, former chief executive officer, Brighton and Sussex University Hospitals)

The responsibility of organisations now is to develop leadership (as well as followership) that will allow an open culture of acknowledgement, but also a more active, analytical seeking out of failings (before they hit the headlines). Do NHS trusts have respect-and-dignity policies that are proactively implemented? Are any trust mangers from Stafford Hospital being struck off ${ }^{17}$ Until this ideological state emerges, we unfortunately need people like Margaret Haywood to show us the cracks. ${ }^{18}$

As to the pragmatic reality of her particular situation, she successfully highlighted travesties that would have otherwise been ignored and she brought about significant real change at the RSCH and nationally. In doing so, however, she compromised some inherent principles in a morally ambiguous manner and could arguably have done things differently:

\footnotetext{
The only regret I have is that the only way to get something done about the complaints which [the hospital] received was to investigate and expose them.
}

MH was struck off by the NMC in April 2009; however, she was reinstated in October 2009 following an out-of-court settlement, with a 1-year caution, and she can now work again as a nurse.

If the principles behind her methods are extended to their logical extremes, we should always use individual patients as means to achieve our ends; we can invade privacy and confidentiality when we feel it is necessary, so long as we ask permission retrospectively; we can hold on to any damaging information (allowing people to continue suffering in the mean time) for as long as needed until it can be brought to public attention with maximum impact; and, finally, we can compromise some of our ethics of duty and ideals if they get in the way of the big picture ('for the greater good').

The bottom line for ethical leadership should therefore be: at whose cost is this allowed to happen? We need to look feelingly at the human condition; we need to act compassionately, especially in a hospital, of all places, rather than at the economic bottom line.

I will see it as a measure of my success here, that members of staff will feel able to speak truth to power. (Duncan Selbie, new chief executive officer, Brighton and Sussex University Hospitals)

\section{Competing interests None.}

Provenance and peer review Not commissioned; externally peer reviewed.

\section{REFERENCES}

1. Werhane PH. Moral imagination and management decision making. New York: Oxford University Press, 1999.

2. Barker PJ. 2009.Nursing Council must review this case [Letters]. The Guardian 2009. http://www.guardian.co.uk/society/2009/apr/18/letters-nursing-councilmargaret-haywood(accessed 18 Jun 2010).

3. NMC Ruling. Reasons for the substantive hearing of the Conduct and Competence Committee panel held at NMC, Centrium, 61 Aldwych, London On 25-28 November 2008 and 14-16 April 2009.

4. Kant I. Grounding for the metaphysics of morals. 3rd edn. Indianapolis, USA: Hackett, 1993. p 30.

5. Brighton and Sussex University Hospitals NHS Trust, PUBLIC INTEREST DISCLOSURES (WHISTLEBLOWING) POLICY 2009

6. Crook D. How to encourage whistleblowing. Journal of Financial Regulation and Compliance 2000;8:326-32.

7. Rowe M, Bendersky C. Workplace justice, zero tolerance and zero barriers: getting people to come forward in conflict management systems. In: Kochan T, Lipsky DB eds. Negotiations and Change: From the Workplace to Society. Ithaca, USA: Cornell University Press, 2002

8. Nursing and Midwifery Council. The code: standards of conduct, performance and ethics for nurses and midwives. http://www.nmc-uk.org/About-us/The-Council/ Code-of-Conduct-for-members-2009/ (accessed Jun 2010)

9. Holmes R, Roy B. The use of postcolonialism in the nursing domain colonial patronage, conversion, and resistance. Adv Nurs Sci 2008 31:42-51.

10. Royal College of Nursing. Defining nursing, 2009. http://www.rcn.org.uk/_data/ assets/pdf file/0003/78564/001983.pdf (accessed 18 Jun 2010).

11. Fleming $\overline{\mathbf{G}}$. Are student nurses too posh to wash? Nursing times.net, 2009 http://www.nursingtimes.net/whats-new-in-nursing/off-duty/beyond-the-bedpan/arestudent-nurses-too-posh-to-wash/5008269.article (accessed 18 Jun 2010).

12. Wade HWR, Forsyth C. Administrative law. 7th and 9th edn. Oxford: Oxford University Press, 2005.

13. Nursing standard. Nursing Standard Patient's Choice Award 2009: Margaret Haywood, whistle blower, 2009. http://nurseawards.rcnpublishing.co.uk/ pcshortlistvote.asp (accessed 18 Jun 2010).

14. Carvell J. Royal College of Nursing launches whistleblower hotline after poll reveals victimisation fears. Society Guardian, 2009. http://www.guardian.co.uk/society/ 2009/may/10/nhs-nurses-hotline-bad-practice (accessed 18 Jun 2010).

15. Porter M. 'All that is necessary for the triumph of evil is that good men do nothing' (or words to that effect): a study of a web quotation. http://tartarus.org/ $\sim$ martin/ essays/burkequote.html (accessed 18 Jun 2010).

16. Maak T, Pless N. Responsible leadership. London: Routledge Press, 2006.

17. Sawer P. Staffordshire hospital scandal: the hidden story, 2009 http://www.telegraph.co.uk/health/healthnews/5030012/Staffordshire-hospitalscandal-the-hidden-story.html (accessed 18 Jun 2010).

18. Tauber Al. Patient autonomy and the ethics of responsibility. Cambridge, MA, USA MIT Press, 2005. ISBN: 026270112X. 